\title{
Expression of RXFP1 Is Decreased in Idiopathic Pulmonary Fibrosis Implications for Relaxin-based Therapies
}

\author{
Jiangning Tan ${ }^{1,2}$, John R. Tedrow ${ }^{1,2}$, Justin A. Dutta ${ }^{1,2}$, Brenda Juan-Guardela ${ }^{3}$, Mehdi Nouraie ${ }^{1,2}$, Yanxia Chu ${ }^{1,2}$, \\ Humberto Trejo Bittar ${ }^{4}$, Kritika Ramani ${ }^{5}$, Partha S. Biswas ${ }^{5}$, Kristen L. Veraldi ${ }^{1,2}$, Naftali Kaminski ${ }^{3}$, Yingze Zhang ${ }^{1,2}$, \\ and Daniel J. Kass ${ }^{1,2}$
}

${ }^{1}$ Dorothy $\mathrm{P}$. and Richard P. Simmons Center for Interstitial Lung Disease, ${ }^{2}$ Division of Pulmonary, Allergy, and Critical Care Medicine, ${ }^{4}$ Department of Pathology, and ${ }^{5}$ Division of Rheumatology, University of Pittsburgh, Pittsburgh, Pennsylvania; and ${ }^{3}$ Section of Pulmonary, Critical Care, and Sleep Medicine, Yale University, New Haven, Connecticut

ORCID ID: 0000-0001-6597-7830 (D.J.K.).

\section{Abstract \\ Rationale: Relaxin is a hormone that has been considered as a potential therapy for patients with fibrotic diseases.}

Objectives: To gauge the potential efficacy of relaxin-based therapies in idiopathic pulmonary fibrosis (IPF), we studied gene expression for relaxin/insulin-like family peptide receptor 1 (RXFP1) in IPF lungs and controls.

Methods: We analyzed gene expression data obtained from the Lung Tissue Research Consortium and correlated RXFP1 gene expression data with cross-sectional clinical and demographic data. We also employed ex vivo donor and IPF lung fibroblasts to test RXFP1 expression in vitro. We tested CGEN25009, a relaxin-like peptide, in lung fibroblasts and in bleomycin injury.

Measurements and Main Results: We found that RXFP1 is significantly decreased in IPF. In patients with IPF, the magnitude of $R X F P 1$ gene expression correlated directly with diffusing capacity of the lung for carbon monoxide $(P<0.0001)$. Significantly less RXFP1 was detected in vitro in IPF fibroblasts than in donor controls.

Transforming growth factor- $\beta$ decreased RXFP1 in both donor and IPF lung fibroblasts. CGEN25009 was effective at decreasing bleomycin-induced, acid-soluble collagen deposition in vivo. The relaxin-like actions of CGEN25009 were abrogated by RXFP1 silencing in vitro, and, in comparison with donor lung fibroblasts,
IPF lung fibroblasts exhibited decreased sensitivity to the relaxin-like effects of CGEN25009.

Conclusions: IPF is characterized by the loss of RXFP1 expression. RXFP1 expression is directly associated with pulmonary function in patients with IPF. The relaxin-like effects of CGEN25009 in vitro are dependent on expression of RXFP1. Our data suggest that patients with IPF with the highest RXFP1 expression would be predicted to be most sensitive to relaxin-based therapies.

Keywords: relaxin; pulmonary fibrosis; transforming growth factor- $\beta$; RXFP1

\section{At a Glance Commentary}

Scientific Knowledge on the Subject: Relaxin and relaxinbased therapies have been considered as potential therapies for pulmonary fibrosis.

What This Study Adds to the Field: We found that expression of the relaxin receptor, $R X F P 1$, is decreased in idiopathic pulmonary fibrosis and is associated with impaired pulmonary function. Understanding how RXFP1 is regulated is critical to the success of relaxin-based therapies in idiopathic pulmonary fibrosis.

(Received in original form September 21, 2015; accepted in final form May 14, 2016)

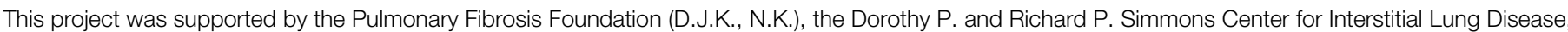

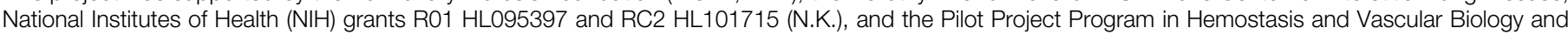
$\mathrm{NIH}$ grant R01 HL126990 (D.J.K.).

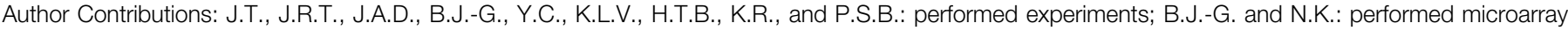

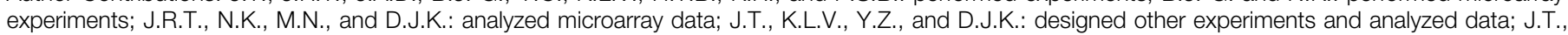
J.R.T., and D.J.K.: wrote the manuscript.

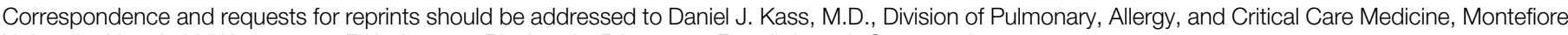
University Hospital NW628, 3459 Fifth Avenue, Pittsburgh, PA 15213. E-mail: kassd2@upmc.edu

This article has an online supplement, which is accessible from this issue's table of contents at www.atsjournals.org

Am J Respir Crit Care Med Vol 194, Iss 11, pp 1392-1402, Dec 1, 2016

Copyright (C) 2016 by the American Thoracic Society

Originally Published in Press as DOI: 10.1164/rccm.201509-18650C on June 16, 2016

Internet address: www.atsjournals.org 
Idiopathic pulmonary fibrosis (IPF) is a progressive and devastating disorder characterized by the unremitting accumulation of activated fibroblasts in the lung, which leads ultimately to respiratory failure. With a median survival of approximately 3-4 years from the time of diagnosis $(1,2)$, IPF is a leading indication for lung transplant (3). One potential therapeutic strategy to use in treating IPF is to interfere with the pathways associated with fibroblast activation and synthesis of extracellular matrix.

The observation that the hormone relaxin could loosen collagen fibers served as a strong rationale for promoting relaxin as a potential therapy for pulmonary fibrosis $(4,5)$. Further evidence in support of this hypothesis came from the study of relaxin-knockout mice, in which there is progressive, age-related multiorgan fibrosis (5-7). Treatment of aged relaxin-null mice with recombinant relaxin reversed pulmonary fibrosis (6). These data suggest that treatment of patients with IPF with relaxin or relaxin agonists might be efficacious. Enthusiasm for this strategy ebbed following the failure of a clinical trial of relaxin therapy for systemic sclerosis (SSc) $(8,9)$. The recent success of relaxin in clinical trials for acute heart failure (10), however, has renewed interest in studying relaxin-based therapies in fibrotic diseases, including IPF $(11,12)$.

Circulating relaxin is encoded by the relaxin 2 ( $R L N 2$ ) gene (5). RLN1 has no known human function, and RLN3 is expressed in the brain (11). The relaxins signal through the $\mathrm{G}$ protein-coupled receptors encoded by the four receptor genes (RXFP1-RXFP4) (13). Relaxin/insulin-like family peptide receptor 1 (RXFP1), whose natural ligand is RLN2, is the only relaxin receptor known to be expressed in the lung (11). Binding of relaxin to RXFP1 recruits $G$ proteins with subsequent activation of adenylyl cyclase and elevation of cAMP (11). Of relevance to fibrosis, induction of nitric oxide synthase 2 downstream of relaxin has been shown to increase nitric oxide/cyclic guanosine monophosphate/protein kinase Gdependent inactivation of the Rho/Rhoassociated coiled-coil-containing protein kinase, leading to cellular relaxation (14). Nitric oxide has also been shown to inhibit profibrotic transforming growth factor (TGF)- $\beta$ signaling by blocking phosphorylation of Smad2 (15). One potential biological explanation for the failure of relaxin in SSc is that there is decreased expression of the relaxin receptor, RXFP1, in fibrosis, and this decrease in RXFP1 gene expression may prevent the protective antifibrotic activities of relaxin signaling. While we cannot answer this question definitively in SSc, data obtained from the Lung Tissue Research Consortium (LTRC; https://www.ltrcpublic.com/), which contains gene expression, demographic, and clinical data in IPF and in donor controls, may help us to predict the potential sensitivity of patients with IPF to relaxin-based therapies. To date, there have been no clinical trials that have tested relaxin in IPF. To investigate the potential application of relaxin-based therapies in IPF, we queried the LTRC gene expression dataset to determine expression of RXFP1 in IPF. We employed a relaxin-like peptide, CGEN25009 (12), as a model of a relaxinbased therapy to test in bleomycin injury and in ex vivo human lung fibroblasts.

\section{Methods}

\section{Ethics Statement}

The institutional review board and the institutional animal care and use committee of the University of Pittsburgh approved this work.

\section{Reagents}

A full list of reagents used in the experiments is available in the online supplement.

\section{Microarray Analysis}

A full description of the RNA isolation and microarray procedures is published elsewhere $(16,17)$. We used publicly available data from the Lung Genomics Research Consortium (http://www.lunggenomics.org/). One hundred thirty-four patients with IPF, 48 subjects with non-IPF interstitial lung disease (non-IPF ILD), and 108 donor control subjects were selected. These data and methods are available in the Gene Expression Omnibus database (accession number GSE47460) (18). The false discovery rate (FDR) was calculated according to the method of Benjamini and Hochberg (19). Data were normalized using a cyclic LOESS algorithm from the Bioconductor suite of R (20). Analyses were performed using BRB-ArrayTools
4.3.0 Stable Release developed by Dr. Richard Simon and the BRBArrayTools Development Team.

\section{Isolation of Human Lung Tissue and Primary Lung Fibroblast Culture}

Donor human fibroblasts were isolated from lungs that appeared to have no injury by histology but were deemed unacceptable for lung transplant. IPF lung fibroblasts were obtained from patients either at explant or at autopsy (21). All fibroblasts were maintained in Dulbecco's modified Eagle's medium supplemented with $10 \%$ fetal bovine serum and were used between passages 3 and 6 .

\section{Bleomycin-induced Lung Injury and CGEN25009 Treatment, Sircol Collagen Assay, Histology, and Flow Cytometry}

Full details of the experimental protocols are available in the online supplement.

\section{Gene Silencing or Overexpression of RXFP1}

Short interfering RNA (siRNA) oligonucleotides targeting the relaxin receptor RXFP1 (SMARTpool) or nontargeting controls were purchased from GE Dharmacon (Lafayette, CO). Plasmids encoding RXFP1 or green fluorescent protein (control) were obtained from OriGene (Rockville, MD). Lentiviral constructs were generated as per the manufacturer's recommendations. Full details of the cell culture conditions are available in the online supplement.

\section{Immunoblotting}

Immunoblotting was performed as previously described (22). Full details are available in the online supplement.

\section{Statistical Analysis}

We used the Mann-Whitney $U$ test, analysis of variance followed by Fisher's least significant difference post hoc test, or the $\chi^{2}$ test to compare data between different groups of subjects. For animal experiments, we used the intraclass correlation coefficient to measure intrarater agreement in Ashcroft scoring. For Ashcroft scoring and for determination of collagen content, we used a generalized linear model with bootstrapping and a robust variance estimator. Univariate analysis was performed by using the Pearson's correlation coefficient of square 
root-transformed gene expression data and clinical data with FVC and diffusing capacity of the lung for carbon monoxide $\left(\mathrm{DL}_{\mathrm{CO}}\right)$. Univariate predictors of FVC and $\mathrm{DL}_{\mathrm{CO}}$ with $P$ values less than 0.2 were then incorporated into multivariate prediction models. Final models were selected by using a backward stepwise approach. Analyses were performed by using Prism 6.0 (GraphPad Software, La Jolla, CA) or STATA 14.0 (StataCorp, College Station, TX) software.

\section{Results}

\section{RXFP1 Expression in IPF, SSc, and Bleomycin Injury}

There has been significant interest in promoting relaxin-based therapies in fibrotic diseases $(5,6,9,14,23)$. To understand the role of endogenous relaxin family signaling in ILD (24), we reanalyzed publicly available microarray data from IPF and controls as described in the METHODS section. Table 1 describes the LTRC cohort. We determined the relative gene expression for RLN2 and RXFP1 (Figure 1A). By microarray analysis of 134 patients with IPF compared with 108 donor control subjects, we found a very small but significant increase in RLN2 gene expression (FDR $<0.05)$. We found that RXFP1 was decreased 2.9-fold in IPF and represented one of the most significantly downregulated genes in IPF compared with controls. To confirm that RXFP1 expression is indeed decreased at the protein level, we employed lysates from lung homogenates derived from patients with IPF and from donor control subjects and performed immunoblotting for RXFP1 (Figures 1B and $1 \mathrm{C}$ ). By immunoblotting, we detected 4.6-fold less RXFP1 in IPF compared with donor controls $(P<0.003 ; \mathrm{n}=4)$. We also examined lung homogenates from patients with SSc by immunoblotting (Figures 1D and $1 \mathrm{E}$ ). We found 2.8-fold less RXFP1 expression in lung homogenates from patients with SSc compared with donor controls $(P=0.05 ; \mathrm{n}=3)$.

Next, we determined if RXFP1 protein levels were lower in the lungs of bleomycininjured mice compared with those of uninjured controls (Figures $1 \mathrm{~F}$ and $1 \mathrm{G}$ ). Bleomycin-injured mice were killed at Day 14 after injury, and their lungs were prepared for immunoblotting. Following bleomycin injury, there was a small but significant decrease in RXFP1 expression ( $P=0.078$ by $t$ test; $\mathrm{n}=6$ per group). We next tested the efficacy of a relaxin-like peptide agonist, CGEN25009, which was effective at preventing bleomycin-induced pulmonary fibrosis (20). In this experiment, we determined if treatment of bleomycin-injured mice with CGEN25009 beginning at either Day 7 or Day 12 after injury would decrease pulmonary fibrosis. We induced pulmonary fibrosis with bleomycin as described in the Methods section. Subcutaneous pumps that dosed CGEN25009 or vehicle were implanted (Figures 1H and 1I).

Ashcroft staining was performed by two blinded reviewers (see Figure E1 in the online supplement). The interrater correlation coefficient was $81 \%$. Following injury with CGEN25009 or vehicle treatment beginning at either Day 7 or

Table 1. Lung Tissue Research Consortium Cohort

\begin{tabular}{|c|c|c|c|c|c|c|}
\hline & Control & IPF & $\begin{array}{c}P \text { Value } \\
\text { (IPF vs. Control) }\end{array}$ & $\begin{array}{l}\text { Non-IPF } \\
\text { ILD }\end{array}$ & $\begin{array}{c}P \text { Value } \\
\text { (Non-IPF } \\
\text { ILD vs. Control) }\end{array}$ & $\begin{array}{c}P \text { Value } \\
\text { (IPF vs. } \\
\text { Non-IPF ILD) }\end{array}$ \\
\hline Number of subjects, $\mathrm{n}(\%)$ & 108 & 134 & & 48 & & \\
\hline Men & $49(45)$ & $94(70)$ & $<0.0001$ & $15(31)$ & 0.11 & $<0.0001$ \\
\hline Women & $59(55)$ & $40(30)$ & & $33(69)$ & & \\
\hline Age, yr, mean (SD) & $63.6(11.4)$ & $63.9(8.2)$ & $<0.0001$ & $56.4(11.4)$ & 0.86 & $<0.0001$ \\
\hline \multicolumn{7}{|l|}{ Ethnicity, $n(\%)$} \\
\hline White & $100(92)$ & $122(91)$ & 0.95 & $44(92)$ & 0.45 & 0.42 \\
\hline African American & $3(2.8)$ & $5(3.7)$ & & $1(2.2)$ & & \\
\hline Hispanic & $1(0.9)$ & $1(0.7)$ & & $2(4.5)$ & & \\
\hline Asian/Pacific Islander & $3(2.8)$ & $2(1.4)$ & & & & \\
\hline Other & $1(0.9)$ & $1(0.7)$ & & & & \\
\hline \multicolumn{7}{|l|}{ Diagnosis, n (\%) } \\
\hline Hypersensitivity pneumonitis & - & - & & $31(64.6)$ & & \\
\hline Rheumatoid arthritis & - & - & & $6(12.5)$ & & \\
\hline Polymyositis/dermatomyositis & - & - & & $4(8.3)$ & & \\
\hline Systemic sclerosis & - & - & & $2(4.2)$ & & \\
\hline Sjögren's syndrome & - & - & & $1(2)$ & & \\
\hline Systemic lupus erythematosus & - & - & & $1(2)$ & & \\
\hline $\begin{array}{l}\text { Undifferentiated connective } \\
\text { tissue disease }\end{array}$ & - & - & & $3(6.3)$ & & \\
\hline \multicolumn{7}{|l|}{ Smoking status, n (\%) } \\
\hline Never & $32(30)$ & $47(35)$ & 0.3 & $21(44)$ & 0.3 & 0.4 \\
\hline Current & $2(1.9)$ & $2(1.5)$ & & 0 & & \\
\hline Ever & $63(58)$ & $81(60)$ & & $26(54)$ & & \\
\hline \multicolumn{7}{|l|}{ Pulmonary function, mean (SD) } \\
\hline $\mathrm{FEV}_{1}, \%$ predicted & 95 (12.6) & 70.5 (18.2) & $<0.0001$ & $69.2(17)$ & $<0.0001$ & 0.58 \\
\hline FVC, \% predicted & 94.4 (13.1) & $63.4(16.9)$ & $<0.0001$ & $67(15.1)$ & $<0.0001$ & 0.13 \\
\hline D $\left\llcorner_{\mathrm{CO}}, \%\right.$ predicted & $84.1(16.7)$ & 46.7 (19.2) & $<0.0001$ & 59 (19) & $<0.0001$ & $<0.0001$ \\
\hline
\end{tabular}

Definition of abbreviations: $\mathrm{DLCO}=$ diffusing capacity of the lung for carbon monoxide; ILD = interstitial lung disease; IPF = idiopathic pulmonary fibrosis. 
A

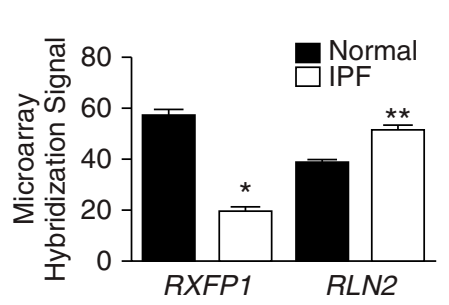

B

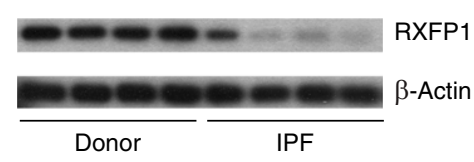

C

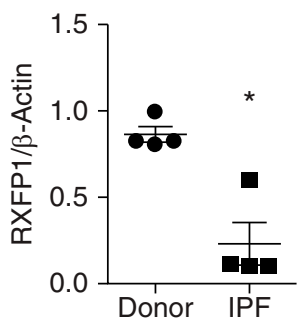

D

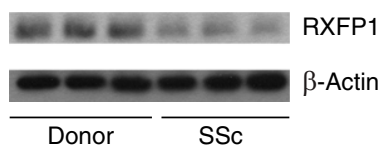

E

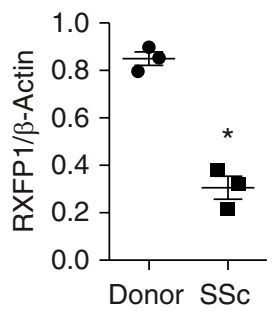

$\mathbf{F}$

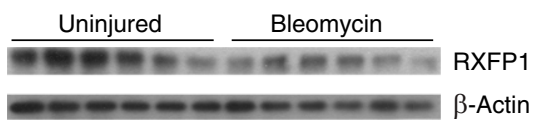

G

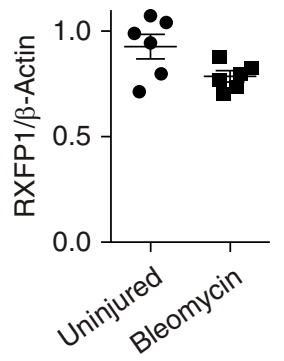

H

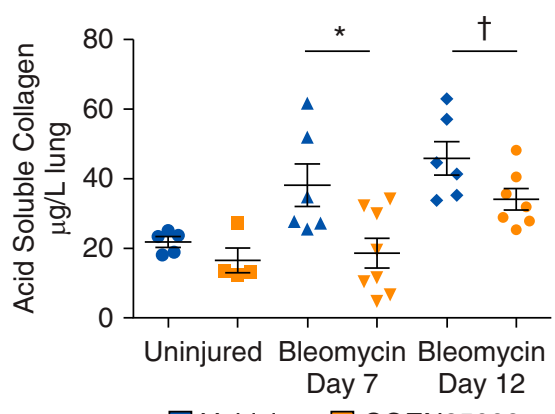

I

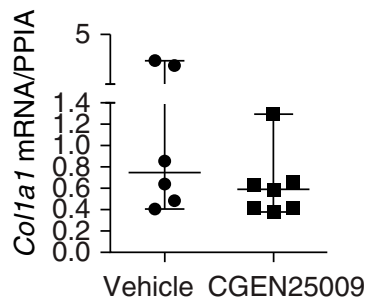

$\mathbf{J}$

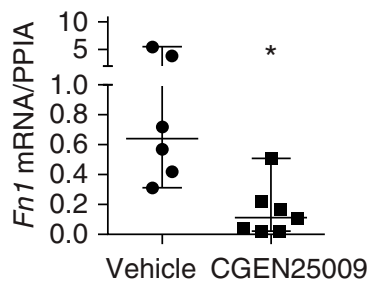

$\mathbf{K}$ Vehicle $\square$ CGEN25009
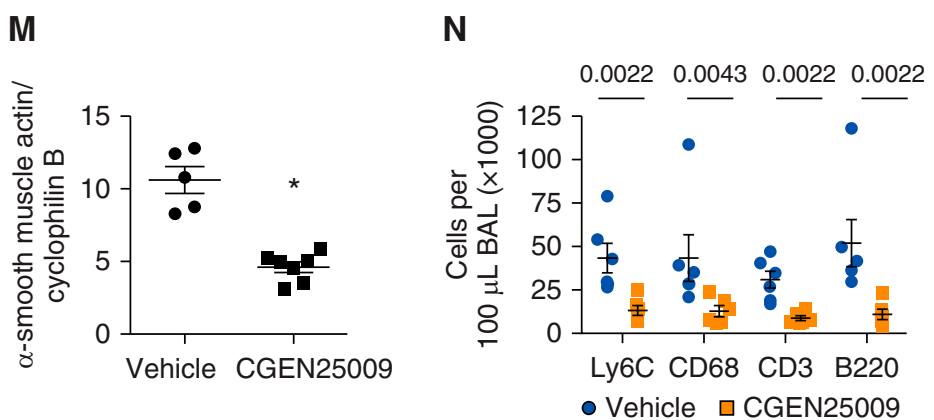

Figure 1. Relaxin/insulin-like family peptide receptor 1 (RXFP1) expression is decreased in pulmonary fibrosis. (A) Gene expression data from the Lung Tissue Research Consortium (107 control subjects and 134 patients with idiopathic pulmonary fibrosis [IPF]) were analyzed for the relaxin receptor, RXFP1, and relaxin 2 (RLN2). RXFP1 was downregulated 2.9-fold in IPF ( ${ }^{*} P<0.0001$ by unpaired $t$ test), and $R L N 2$ was significantly increased in IPF but with a fold change of 1.17 ( ${ }^{\star \star} P<0.003$ by unpaired $t$ test). (B) Whole-lung homogenates from patients with IPF and donor control subjects were subjected to immunoblotting for RXFP1 as described in the METHODS section of the main text. (C) Band intensity of RXFP1 was normalized to $\beta$-actin using ImageJ software (National Institutes of Health, Bethesda, MD) for the immunoblot shown in $B$ as described in the MetHoDs section ( ${ }^{*} P<0.0029$ by MannWhitney $U$ test; $n=4)$. (D) Immunoblot for RXFP1 from systemic sclerosis (SSc) lungs and donor controls. $(E)$ ImageJ quantification of RXFP1 band intensity for the immunoblot shown in $D\left({ }^{*} P=0.05\right.$ by Mann-Whitney $U$ test; $\left.\mathrm{n}=3\right)$. ( $F$ ) Immunoblots for RXFP1 from whole-lung homogenates derived from mouse lungs 14 days after bleomycin injury ( $n=6$ per group). (G) Image quantification of RXFP1 band intensity for the immunoblots shown in $F$ ( $^{\star} P=0.078$ by Mann-Whitney $U$ test; $n=6$ ). $(H)$ Mice were injured with bleomycin and then treated with CGEN25009 beginning at Day 7 or Day 12 after injury. Lungs were collected at Day 21 after injury, and collagen was quantified by performing Sircol assays (Biocolor, Carrickfergus, UK). Using a generalized linear 
Day 12 after injury, we observed a $22 \%$ reduction in Ashcroft scoring with CGEN25009-treated animals compared with vehicle-treated animals $(P=0.032)$. The results of histological experiments from multiple animals are shown in Figures E1 and E2. Lungs were processed for determination of acid-soluble collagen content. Treatment of bleomycin-injured mice with CGEN25009 beginning at Day 7 or Day 12 after injury decreased acidsoluble collagen content. In a second experiment, we employed animals engineered to express the tdTomatoenhanced red fluorescent protein in Colla2 ${ }^{+}$cells (Figure E3). Following bleomycin-induced injury and CGEN25009 treatment, beginning at Day 12, decreases in fibronectin and $\alpha$-smooth muscle actin $(\alpha$-SMA) mRNA were observed in flowsorted tdTomato ${ }^{+}$cells compared with vehicle controls (Figures 1I-1K). Immunoblotting of whole-lung homogenates showed significantly less $\alpha$-SMA in CGEN25009-treated mice (Figures 1L and 1M). Analysis of the bronchoalveolar lavage showed significant reductions in neutrophils, macrophages, $\mathrm{T}$ cells, and B cells in CGEN25009-treated mice compared with vehicle controls (Figure 1N). Thus, CGEN25009 decreased several measures of bleomycin-induced lung injury in mice: acid-soluble collagen content; expression of the myofibroblast differentiation marker $\alpha$-SMA; and inflammation as measured by the decreased accumulation of neutrophils, macrophages, and lymphocytes.

\section{RXFP1 Expression Is Associated with Distinct Patterns of Gene Expression in IPF}

We found that RXFP1 expression is decreased in IPF. To determine the potential clinical implications of RXFP1 gene expression in IPF, we returned to the LTRC data. Considering only the patients with IPF, we determined the effect of $R X F P 1$ expression on pulmonary function
(Figures 2A-2E) and on whole-lung gene expression (Figure 2F).

We arranged the patients with IPF into four equal quartiles based on RXFP1 expression. As shown in Figure 2A, RXFP1 expression increased from quartiles 1-4 $(P<0.0001$ for trend by one-way analysis of variance; $n=33-34$ /quartile). There was no relationship between sex (Figure $2 \mathrm{~B}$ ) ( $P=$ not significant by $\chi^{2}$ for trend), age (Figure $2 \mathrm{C}$ ), and RXFP1 quartile. To determine if $R X F P 1$ gene expression was associated with pulmonary function, we performed univariate regression analysis (Figures 2D and 2E and Table 2). By univariate analysis, we found that RXFP1 gene expression predicted FVC in IPF and in a cohort of IPF and non-IPF ILD. We also found that RXFP1 gene expression predicted $\mathrm{DL}_{\mathrm{CO}}$ for IPF and non-IPF ILD. Next, to adjust for the confounding effects of clinical and demographic variables, we performed multivariate regression analyses (Table 3), employing the gene expression data combined with demographics and cross-sectional measures of exercise tolerance and quality of life derived from the LTRC data. In our multivariate model, we found that RXFP1 gene expression was directly associated with FVC and DLCO.

Having shown clinically relevant differences in patients with IPF based on gene expression for RXFP1, we hypothesized that patients with IPF would be "transcriptomically" distinct based on $R X F P 1$ gene expression. To test this hypothesis, we generated a heatmap of the patients with IPF and arranged the patients in columns based on increasing RXFP1 expression (Figure 2F). Each of the quartiles is marked by a break. Patients in quartiles 1 and 2 were defined as "RXFP1low," and patients in quartiles 3 and 4 were defined as "RXFP1-high." With this analysis, we found that 5,371 genes $($ FDR $<0.05)$ were differentially expressed between the RXFP1-high and RXFP1-low patients. The 20 most upregulated and most downregulated genes are presented in Tables E1 and E2, respectively. We subjected the differentially expressed gene list to Ingenuity Pathway Analysis (QIAGEN, Redwood City, CA). Table E3 shows the top represented molecular and cellular function networks based on $R X F P 1$ gene expression. Taken together, these data suggest that RXFP1 gene expression is associated with a large number of differentially expressed genes and may identify distinct clinical and transcriptomic subphenotypes of IPF.

\section{TGF- $\beta$ Regulates RXFP1 in Donor and IPF Lung Fibroblasts}

We have shown above that RXFP1 expression is decreased in IPF and that lower expression of RXFP1 may have clinically relevant implications. In the next set of experiments, we determined if the loss of RXFP1 was mechanistically related to a common pathologic feature of fibrosis-differentiation of fibroblasts to myofibroblasts. TGF- $\beta$ signaling is central to this pathway (25). To test this hypothesis, donor or IPF human lung fibroblasts (26) were stimulated in vitro with TGF- $\beta$ (Figures $3 \mathrm{~A}-3 \mathrm{C}$ ). After stimulation with TGF- $\beta$ or vehicle control, cell lysates were subjected to immunoblotting for RXFP1. At baseline, RXFP1 protein expression was significantly higher in donor fibroblasts than in IPF fibroblasts (Figures $3 \mathrm{~A}$ and $3 \mathrm{~B}$ ). Following stimulation with TGF- $\beta$, RXFP1 expression decreased significantly in both donor and IPF-derived fibroblasts. It is notable that expression of RXFP1 decreased to undetectable levels in IPF fibroblasts following stimulation with TGF- $\beta$. Because we found differences in RXFP1 in IPF by microarray analysis, we hypothesized that we would detect decreased RXFP1 mRNA in lung fibroblasts following TGF- $\beta$ stimulation (Figure 3C). Indeed, we found, in parallel to our findings at the protein level, that mRNA for RXFP1 decreased after TGF- $\beta$

Figure 1. (Continued). model with bootstrapping and a robust variance estimator, we found that treatment of bleomycin-injured animals with CGEN25009 was associated with a significant decrease in acid-soluble collagen (mean effect, $-15.8 ;{ }^{*, \dagger} P<0.001$ ). () Quantitative reverse transcription-polymerase chain reaction for Col1a1, performed on flow-sorted tdTomato ${ }^{+}$cells from bleomycin-injured mice treated with CGEN25009 $(n=7)$ or vehicle $(n=6)$ beginning at Day 12 after injury. Data shown in I-K were analyzed by using the Kolmogorov-Smirnov test, and the bars represent the median \pm range. ( $J$ ) Fibronectin $\left({ }^{*} P<0.008\right)$. (K) Acta2 $\left(\alpha\right.$-smooth muscle actin $\left[\alpha\right.$-SMA]) ( $\left.{ }^{*} P<0.04\right)$. (L) Immunoblots of whole-lung homogenates for $\alpha$-SMA from bleomycin-injured mice treated with vehicle $(n=5)$ or CGEN25009 $(n=7)$. (M) Densitometry results for immunoblots shown in $L\left({ }^{*} P=0.0025\right.$ by Mann-Whitney $U$ test). ( $N$ ) Flow cytometric analysis for cell-specific markers of cells isolated from the bronchoalveolar lavage (BAL) of bleomycin-injured mice treated with CGEN25009 ( $n=7$ ) or vehicle $(n=6)$ beginning at Day 12 after injury: Ly6C (neutrophils), CD68 (macrophages), CD3 (T cells), and B220 (B cells). Data were analyzed by Mann-Whitney $U$ test. $P$ values are indicated in the figure. All bars except those in $/ K$ represent the mean $\pm \mathrm{SEM}$. Acta2 =actin, $\alpha 2 ;$ Col1a1 = collagen type $\mathrm{I}, \alpha 1 ; F n 1=$ fibronectin 1 . 
A
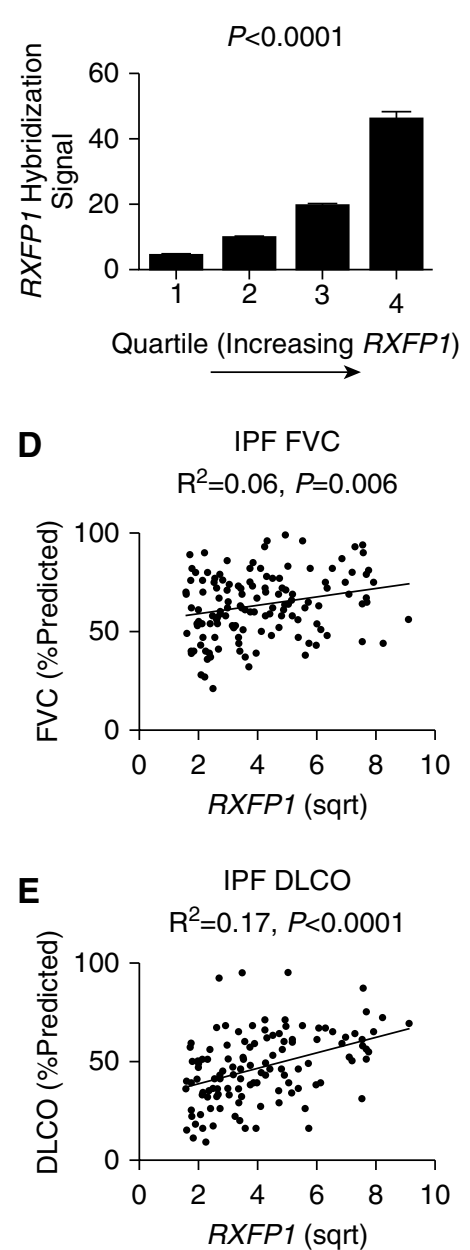

B
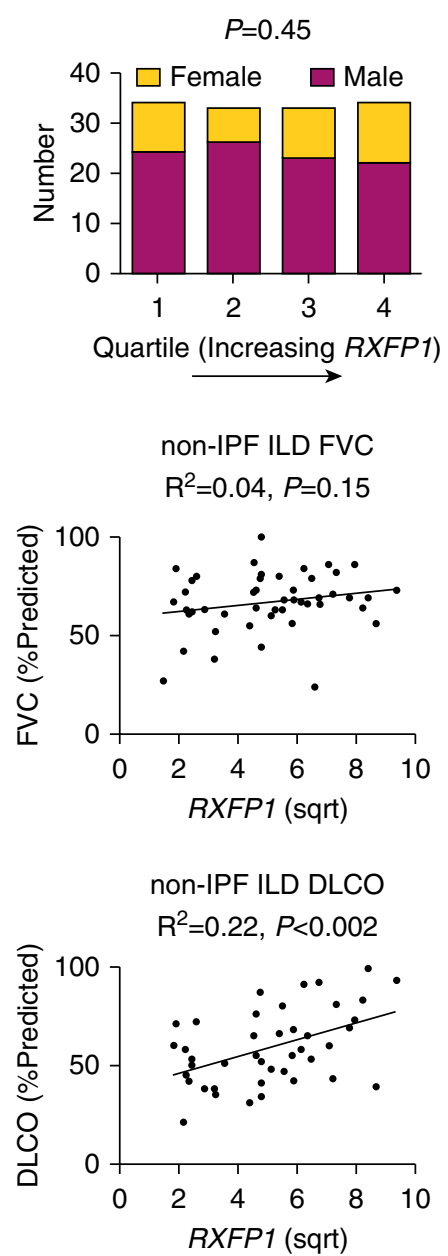

C

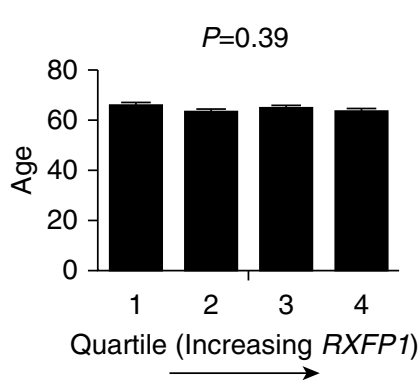

IPF + non-IPF ILD FVC $\mathrm{R}^{2}=0.06, P=0.001$

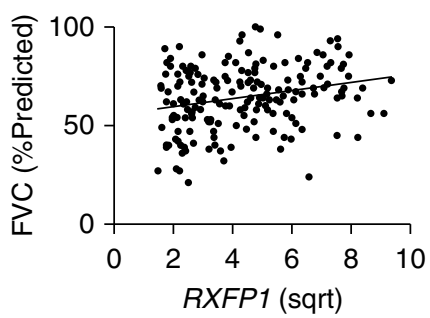

IPF + non-IPF ILD DLCO $\mathrm{R}^{2}=0.22, P<0.0001$

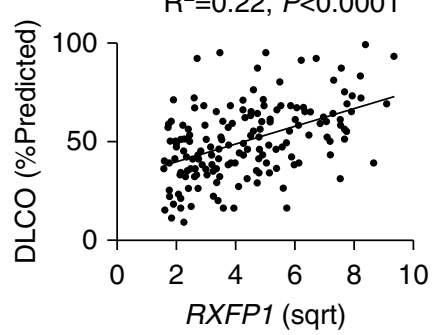

$\mathbf{F}$

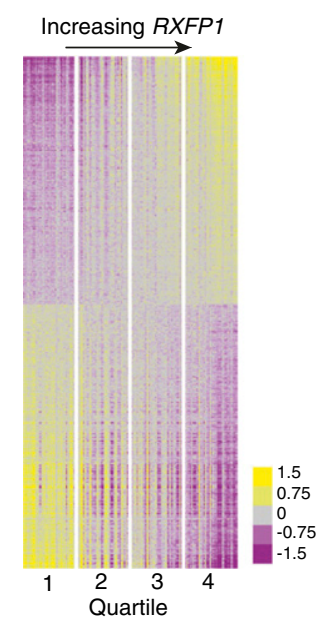

Figure 2. Relaxin/insulin-like family peptide receptor 1 (RXFP1) gene expression correlates directly with diffusing capacity of the lung for carbon monoxide $(\mathrm{DLCO})$ in idiopathic pulmonary fibrosis (IPF) and is associated with a distinct gene expression profile. (A) Considering only the patients with IPF from the Lung Tissue Research Consortium, we organized patients into four quartiles based on increasing expression of RXFP1 and compared their demographic and clinical data $(P<0.0001$ for trend by one-way analysis of variance; $n=33-34$ /quartile). (B) Sex representation in each quartile. Women are represented in yellow and men in purple, showing no significant difference based on sex across quartiles $\left(P=\right.$ not significant by test $\chi^{2}$ for trend). $(C)$ No significant effects were observed with regard to age. ( $D$ and $E$ ) Pearson correlation coefficients of FVC and DLco as a function of square root (sqrt)-transformed RXFP1 gene expression for IPF, non-IPF interstitial lung disease (non-IPF ILD), and the two together. $R^{2}$ and $P$ values are indicated in the figure. ( $F$ ) Differentially expressed genes in patients with IPF based on RXFP1 expression are represented by a heatmap. Each column represents a patient, and each row represents a gene. The color bar represents fold change. Between the upper two and lower two quartiles, 5,371 genes were differentially expressed. All bars represent the mean \pm SEM.

stimulation and was lower in unstimulated IPF lung fibroblasts than in donor controls. We performed a dose-response analysis with TGF- $\beta$ and found that the maximum suppression of RXFP1 expression was observed at a dose of $10 \mathrm{ng} / \mathrm{ml}$ (Figures 3D and 3E).

TGF- $\beta$ signals through either Smad or non-Smad pathways. Next, we therefore determined if the Smad signaling inhibitor (TGF- $\beta$ receptor I/activin-like kinase receptor 5 inhibitor) SB431542 (27) would block the TGF- $\beta$-mediated loss of RXFP1 in donor fibroblasts. To test this hypothesis, donor lung fibroblasts were incubated in the presence of SB431542 and then stimulated with TGF- $\beta$ for 24 hours (Figures $3 \mathrm{~F}$ and $3 \mathrm{G}$ ). Without SB431542, stimulation with TGF- $\beta$ decreased expression of RXFP1. There was no effect of SB431542 on RXFP1 expression without TGF- $\beta$. SB431542 completely blocked the effect of TGF- $\beta$ on RXFP1 expression. This suggests that the loss of RXFP1 in response to TGF- $\beta$ is dependent on classical Smad signaling.
We next determined the effect of CGEN25009 on expression of RXFP1, collagen I, and $\alpha$-SMA (Figures $3 \mathrm{H}-3 \mathrm{~K}$ ). Donor fibroblasts were incubated with CGEN25009, followed by stimulation with TGF- $\beta$. We found that CGEN25009 was able to prevent the loss of RXFP1 associated with TGF- $\beta$ treatment. In addition, CGEN25009 prevented the augmented expression of collagen I and $\alpha$-SMA associated with TGF- $\beta$. This observation supports previous studies of recombinant relaxin on myofibroblast differentiation $(28,29)$. 
Table 2. Univariate Predictors of Diffusing Capacity of the Lung for Carbon Monoxide and Percent Predicted FVC

\begin{tabular}{|c|c|c|c|c|c|c|}
\hline & \multicolumn{3}{|c|}{ DLco } & \multicolumn{3}{|c|}{ FVC \% Predicted } \\
\hline & $\mathbf{n}$ & Standardized $\beta$ & $P$ Value & $\mathbf{n}$ & Standardized $\beta$ & $P$ Value \\
\hline Age & 121 & 0.20 & 0.025 & 131 & 0.27 & 0.001 \\
\hline Male sex & 121 & -0.08 & 0.4 & 131 & -0.11 & 0.2 \\
\hline Ever cigarette smoking & 119 & -0.14 & 0.13 & 128 & 0.02 & 0.8 \\
\hline Pack-years of smoking (square root) & 119 & -0.25 & 0.007 & 128 & -0.03 & 0.8 \\
\hline Years since quitting smoking (square root) & 75 & 0.29 & 0.010 & 79 & 0.02 & 0.8 \\
\hline Other smoking & 119 & 0.04 & 0.6 & 128 & 0.07 & 0.4 \\
\hline SGRQ score & 119 & -0.48 & $<0.001$ & 128 & -0.34 & $<0.001$ \\
\hline Weight & 121 & 0.15 & 0.1 & 131 & -0.02 & 0.8 \\
\hline Height & 121 & 0.01 & 0.9 & 131 & -0.08 & 0.4 \\
\hline Walking distance (m) & 104 & 0.45 & $<0.001$ & 114 & 0.37 & $<0.001$ \\
\hline SF-12 PCS & 119 & 0.38 & $<0.001$ & 128 & 0.29 & 0.001 \\
\hline SF-12 MCS & 119 & 0.01 & 0.9 & 128 & 0.07 & 0.4 \\
\hline RXFP1 (square root) & 121 & 0.42 & $<0.001$ & 131 & 0.24 & 0.006 \\
\hline
\end{tabular}

Definition of abbreviations: $\mathrm{D} \mathrm{LCO}_{\mathrm{C}}$ diffusing capacity of the lung for carbon monoxide; $\mathrm{MCS}=$ mental component summary; $\mathrm{PCS}=$ physical component summary; RXFP1 = relaxin/insulin-like family peptide receptor 1; SF-12 = 12-item Short Form Health Survey; SGRQ=St. George's Respiratory

Questionnaire.

\section{Relaxin-like Effects of CGEN25009 Are Dependent upon RXFP1 Expression}

If there is a lack of RXFP1 expression, is relaxin family signaling decreased in IPF lungs? If relaxin family signaling is indeed impaired in IPF, it would suggest that only a subset of patients with relatively higher expression of RXFP1 would be predicted to respond to relaxin-based therapies. To test this hypothesis, we stimulated donor fibroblasts with the relaxin-like peptide CGEN25009 in the presence or absence of RXFP1 gene silencing by siRNA and determined the effect on multiple markers of myofibroblast function. Cells were incubated with nontargeting siRNA
(siControl) or RXFP1-targeting siRNA (siRXFP1) oligonucleotides and then stimulated with CGEN25009. Cells were then lysed and processed for immunoblotting for phosphorylated and total myosin light chain 20 (MLC20), a marker of myofibroblast contractility (14), collagen I, and the myofibroblast marker $\alpha$-SMA. In the presence of siRXFP1, RXFP1 protein expression as determined by our immunoblotting conditions was undetectable (Figures $4 \mathrm{~A}$ and $4 \mathrm{~B}$ ). In the presence of normal RXFP1 expression, stimulation of donor lung fibroblasts led to decreased phosphorylation of MLC20 (Figures 4A and 4C). However, following silencing of RXFP1, phosphorylation of

Table 3. Multivariate Analysis of Predictors of FVC and Diffusing Capacity of the Lung for Carbon Monoxide in Patients with Idiopathic Pulmonary Fibrosis

\begin{tabular}{lcr}
\hline & $\boldsymbol{\beta}(\mathbf{9 5 \%}$ Cl) & $\boldsymbol{P}$ Value \\
FVC $^{*}$ & & \\
Age & $0.55(0.21$ to 0.88$)$ & 0.002 \\
Walking distance (m) & $0.05(0.03$ to 0.07$)$ & 0.001 \\
RXFP1 (square root) & $2.29(0.78$ to 3.81$)$ & 0.003 \\
DLCo & & 0.008 \\
Age & $0.43(0.11$ to 0.76$)$ & 0.003 \\
Walking distance $(m)$ & $0.04(0.01$ to 0.07$)$ & $<0.001$ \\
RXFP1 (square root) & $3.41(2.02$ to 4.80$)$ & 0.001 \\
SGRQ score & $-0.26(-0.41$ to -0.11$)$ \\
\hline
\end{tabular}

Definition of abbreviations: $\mathrm{Cl}=$ confidence interval; $\mathrm{D}\left\llcorner_{\mathrm{CO}}=\right.$ diffusing capacity of the lung for carbon monoxide; RXFP1 = relaxin/insulin-like family peptide receptor 1; SGRQ = St. George's Respiratory Questionnaire.

Variables with $P \leqslant 0.2$ in univariate analysis were entered into both models. Final models were selected by using a backward stepwise approach.

${ }^{*} \mathrm{n}=114 ; R^{2}=0.26$.

${ }^{+} \mathrm{n}=103 ; R^{2}=0.49$ (one outlier was removed).

MLC20 actually increased, and the effect of CGEN25009 on phosphorylation of MLC20 was no longer present. Similarly, stimulation of siControl cells with CGEN25009 decreased collagen I expression (Figures 4A and 4D). With loss of RXFP1 expression, collagen I expression was increased, and the decrease of collagen I observed with CGEN25009 was no longer present. CGEN25009 completely blocked expression of $\alpha$-SMA in siControl cells, but this effect was lost following silencing of RXFP1 (Figures 4A and 4E).

These results collectively support the hypotheses that myofibroblast function is critically linked to RXFP1 expression and that the relaxin-like effects of CGEN25009 are dependent on RXFP1 expression. These results further support an earlier report that the antimyofibroblast effects of relaxin depend on expression of RXFP1 (29). Hypothesizing that donor and IPF fibroblasts express different levels of RXFP1 at baseline, we next determined if these cells exhibited different sensitivity to CGEN25009. To test this possibility, donor or IPF fibroblasts were incubated in the presence of CGEN25009 ranging from 1 to $350 \mathrm{nM}$. Immunoblotting for phosphorylated and total MLC20 was performed (Figures $4 \mathrm{~F}$ and $4 \mathrm{G}$ ). We found higher phosphorylation of MLC20 in IPF fibroblasts than in donor fibroblasts in the presence of the lowest concentration of CGEN25009. Loss of phosphorylation of MLC20 was observed at $35 \mathrm{nM}$ in donor lung fibroblasts and at $350 \mathrm{nM}$ in IPF lung fibroblasts. Densitometry of the 
A

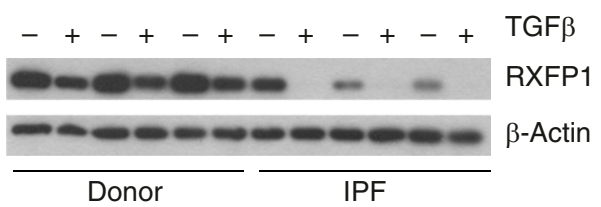

B

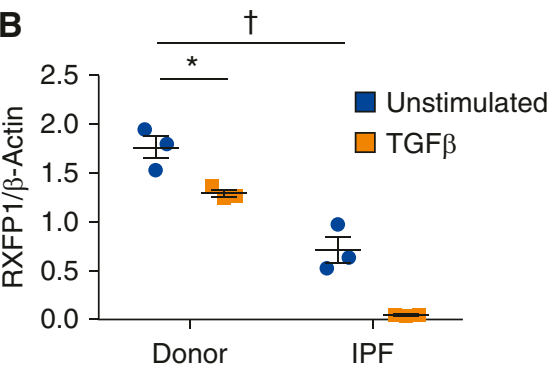

D

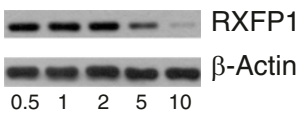

[TGF $\beta] \mathrm{ng} / \mathrm{mL}$
E

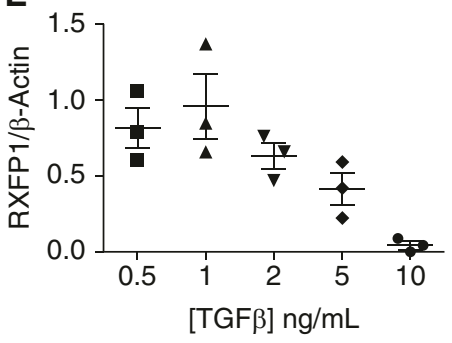

I

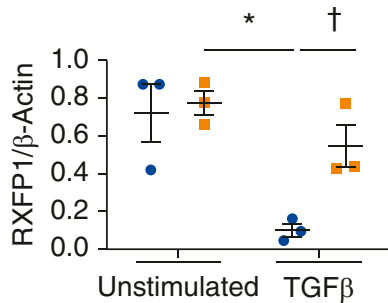

Unstimulated TGF $\beta$
$\mathbf{F}$

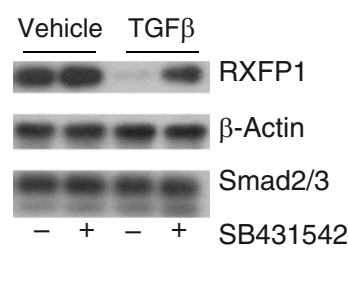

J

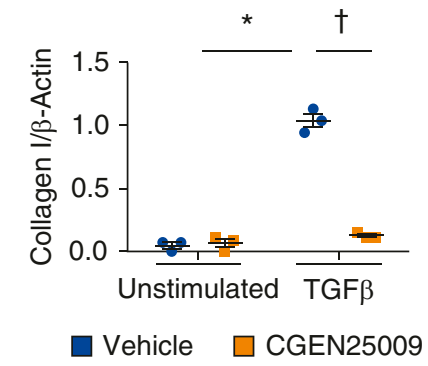

Vehicle

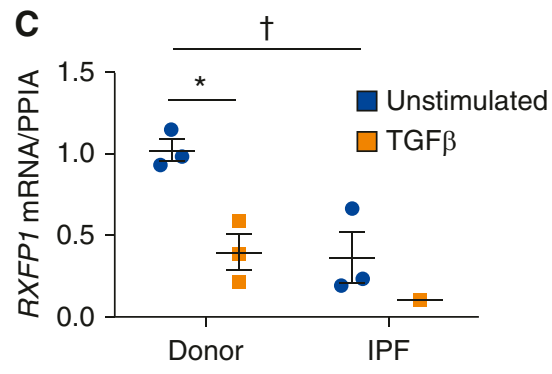

G

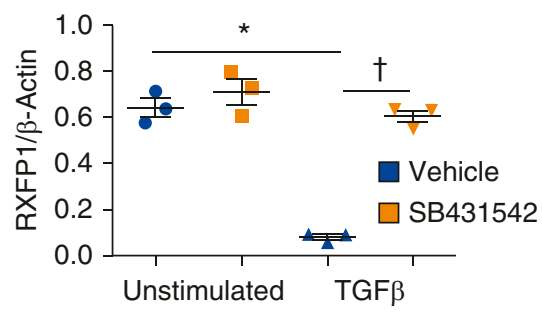

H

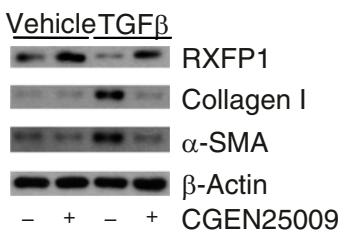

K

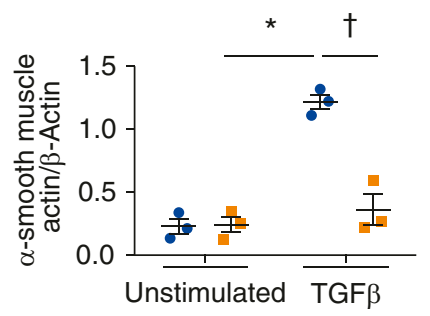

Figure 3. Transforming growth factor (TGF)- $\beta$ decreases expression of relaxin/insulin-like family peptide receptor 1 (RXFP1) in human lung fibroblasts. Human lung fibroblasts were isolated from patients with idiopathic pulmonary fibrosis (IPF) and donor control subjects as described in the METHODs section in the main text. Cells were cultured in the presence or absence of TGF- $\beta$. (A) Immunoblotting was performed for RXFP1 and $\beta$-actin. Decreased expression of RXFP1 in normal and IPF lung fibroblasts was observed in response to TGF- $\beta$. IPF lung fibroblasts also showed decreased expression of RXFP1 at baseline compared with normal lung fibroblasts. (B) Quantification of RXFP1 band intensity using Image J software $\left(^{*, \dagger} P<0.005\right.$ by two-way analysis of variance [ANOVA]; $n=3$ per group). (C) Quantitative reverse transcription-polymerase chain reaction was performed for RXFP1 and peptidylprolyl isomerase A (PPIA) under the same conditions as described in $B$. In response to TGF- $\beta$, mRNA for RXFP1 was significantly decreased in donor lung fibroblasts, and, at baseline, RXFP1 mRNA was significantly decreased in IPF fibroblasts compared with donor fibroblasts ${ }^{*, \dagger} P<0.005$ by two-way ANOVA; $n=3$ per group). In two of three lines tested, mRNA for RXFP1 in IPF fibroblasts following TGF- $\beta$ was undetectable. (D) Donor lung fibroblasts were stimulated with TGF- $\beta$ at different concentrations, and the lysates were processed for immunoblotting for RXFP1. (E) Quantification of immunoblots shown in $D$ by using ImageJ software $(P<0.0004$ by one-way ANOVA for left-to-right trend). ( $F$ ) Donor lung fibroblasts were stimulated with TGF- $\beta$ in the presence of the activin-like kinase receptor 5 inhibitor SB431542 to inhibit Smad signaling. RXFP1 expression was significantly decreased following TGF- $\beta$, and this response was completely abrogated by preincubation with SB431542. (G) Quantification of RXFP1 band from immunoblots shown in $F\left({ }^{\star} P<0.05\right.$ by two-way ANOVA; $\left.n=3\right)$. (H) Donor lung fibroblasts were stimulated first with CGEN25009, followed by TGF- $\beta$. Cells were then lysed and processed for immunoblotting for RXFP1, collagen I, $\alpha$-smooth muscle actin $(\alpha-S M A)$, and $\beta$-actin. Quantification was performed using Image J software for (I) RXFP1, (J) collagen I, and $(K) \alpha$-smooth muscle actin. For $I-K,{ }^{*, \dagger} P<0.05$ by two-way ANOVA. All bars represent the mean \pm SEM.

immunoblots was plotted as a function of the logarithmic scale of the concentrations of CGEN25009. The best-fit curve estimated that the half-maximal inhibitory concentrations of CGEN25009 were $22 \mathrm{nM}$ in donor fibroblasts and $320 \mathrm{nM}$ in IPF fibroblasts. These data support the conclusion that IPF lung fibroblasts are less sensitive to CGEN25009 than donor lung fibroblasts. We next determined if overexpression of RXFP1 in IPF fibroblasts would restore sensitivity to CGEN25009. We infected IPF fibroblasts with empty (green fluorescent protein) or RXFP1expressing lentiviral constructs, followed by stimulation with escalating doses of CGEN25009 (Figures 4H and 4I). We found that, with overexpression of RXFP1 in these experimental conditions, the halfmaximal inhibitory concentration of
CGEN25009 in IPF fibroblasts was reduced from $838 \mathrm{nM}$ to $18.7 \mathrm{nM}$, a 45 -fold change.

\section{Discussion}

We found that RXFP1 gene expression is significantly decreased in the lungs of patients with IPF. Our findings were corroborated by studies with ex vivo lung 
A

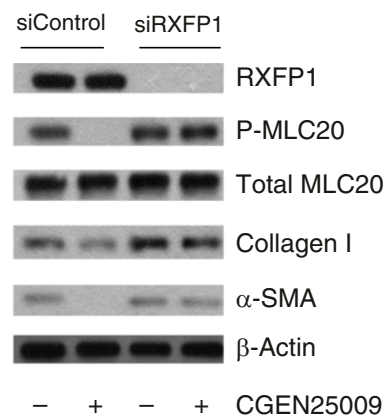

D

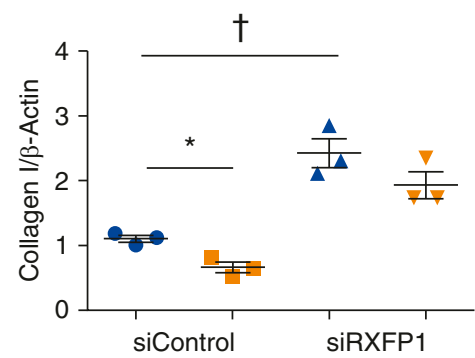

$\mathbf{F}$

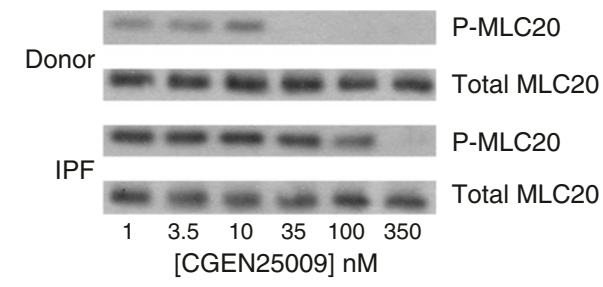

E
C

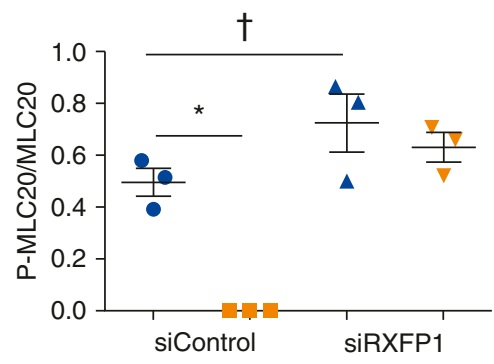

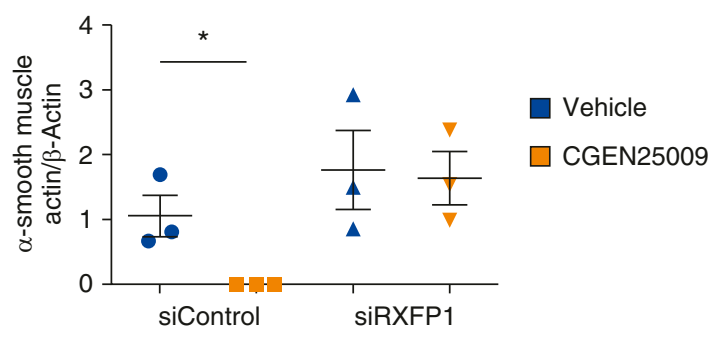

G

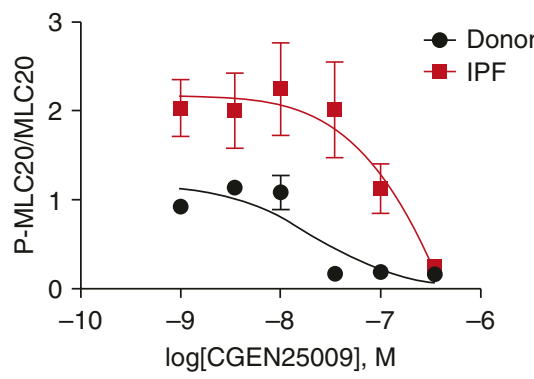

H

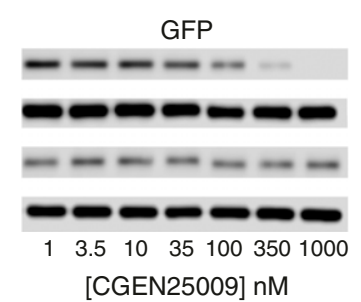

RXFP1

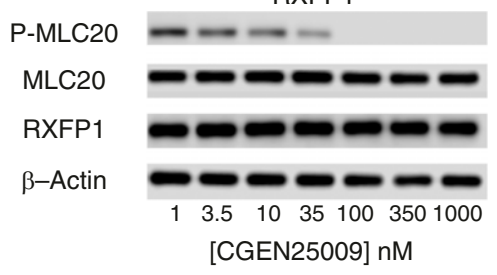

I

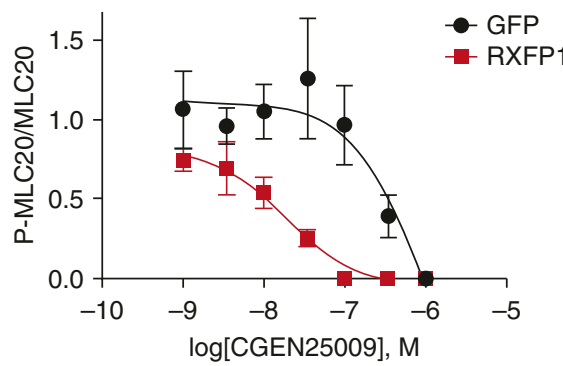

Figure 4. Sensitivity of fibroblasts to CGEN25009 is dependent on relaxin/insulin-like family peptide receptor 1 (RXFP1) expression. Donor lung fibroblasts were incubated with nontargeting short interfering RNA (siRNA) oligonucleotides (siControl) or RXFP1-targeting siRNA oligonucleotides (siRXFP1) and then stimulated with the relaxin-like peptide CGEN25009. (A) Immunoblots for RXFP1, phosphorylated myosin light chain 20 (P-MLC20) and total MLC20, collagen I, and $\alpha$-smooth muscle actin $\left(\alpha\right.$-SMA). Quantification of band intensity was performed, and data were analyzed by two-way analysis of variance. (B) RXFP1 ( ${ }^{*} P<0.05$, siControl + vehicle vs. siRXFP1 + vehicle; $n=3)$. (C) P-MLC20/total MLC20 $\left({ }^{\star} P<0.05\right.$ for siControl + vehicle vs. siControl + CGEN25009; ${ }^{\dagger} P<0.05$ for siControl + vehicle vs. siRXFP1 + vehicle; $n=3)$. (D) Collagen I $\left({ }^{*} P<0.05\right.$ for siControl + vehicle vs. siControl + CGEN25009; ${ }^{\dagger} P<0.05$ for siControl + vehicle vs. siRXFP1 + vehicle; $n=3)$. (E) $\alpha$-SMA ( ${ }^{*} P<0.05$ for siControl + vehicle vs. siControl+CGEN25009; $\left.n=3\right)$. (F) Donor and IPF lung fibroblasts were incubated with escalating concentrations of CGEN25009 and subjected to immunoblotting for phosphorylated MLC20 and total MLC20. (G) Dose-response curves for IPF $(n=3)$ and donor $(n=3)$ lung fibroblasts as a logarithmic function of the concentration of CGEN25009, showing an increased half-maximal inhibitory concentration for CGEN25009 in IPF lung fibroblasts compared with normal controls $(n=3)$. (H) IPF fibroblasts were infected with control (green fluorescent protein [GFP]) or RXFP1-expressing lentiviral particles and then stimulated with escalating concentrations of CGEN25009. Lysates were subjected to immunoblotting for phosphorylated and total MLC20, RXFP1, and $\beta$-actin. () Dose-response curves for RXFP1-infected and GFP-infected lung fibroblasts as a logarithmic function of the concentration of CGEN25009 $(n=3)$. All bars represent the mean \pm SEM. IPF = idiopathic pulmonary fibrosis. 
fibroblasts from patients with IPF and donor control subjects stimulated with the central profibrotic signal TGF- $\beta$. The reduction of RXFP1 in bleomycin injury was far less vigorous. These findings have potential ramifications for translating relaxin-based therapies in IPF. First, in the cross-sectional LTRC dataset, we found that RXFP1 gene expression was a significant predictor of FVC and $\mathrm{DL}_{\mathrm{CO}}$ by univariate and multivariate analyses. Second, RXFP1high patients and $R X F P 1$-low patients, who all have IPF, were distinguished from each other by 5,371 genes. Third, we found that a relaxin-like peptide, CGEN25009, required RXFP1 expression to transduce downstream cell signaling in fibroblasts. IPF fibroblasts that expressed significantly less RXFP1 than donor controls were 10-fold less sensitive to CGEN25009 than donor lung fibroblasts. When we restored expression of RXFP1 by lentivirusmediated expression, we resensitized IPF fibroblasts to the actions of CGEN25009. These data collectively suggest that patients with IPF may be less sensitive to the protective effects of relaxin-based therapies. Strategies to enhance RXFP1 expression would be predicted to sensitize patients with IPF to the effects of relaxin-based therapies.

Little is known about transcriptional regulation of RXFP1 expression. We found that RXFP1 expression was reduced in IPF fibroblasts and that expression was reduced even further in the presence of TGF- $\beta$. These data support previous observations that TGF- $\beta$ is associated with reduced expression of RXFP1 (30). In our hands, supraphysiologic in vitro concentrations of TGF- $\beta$ were observed to decrease RXFP1 in IPF fibroblasts. This suggests that stimuli other than TGF- $\beta$ may decrease RXFP1 expression in IPF. Incubation of IPF fibroblasts with SB431542 alone did not restore expression of RXFP1 in IPF fibroblasts to that of control fibroblasts (data not shown). Because we detected low expression of RXFP1 by microarray in IPF, we hypothesize that the mechanisms driving down $R X F P 1$ are transcriptional. Dysregulation of microRNAs or differential methylation of RXFP1 may be at play here. External signals, perhaps hormonal, may regulate expression of $R X F P 1(31,32)$. $R X F P 1$ expression in IPF in our dataset did not differ by sex, however, suggesting that the loss of RXFP1 in fibrosis is independent of sex. So, the answer to why RXFP1 is reduced in IPF remains enigmatic. We did find that incubation of donor lung fibroblasts with CGEN25009 prevented the TGF- $\beta$-mediated loss of RXFP1. Progression of IPF may be associated with temporal decreases in RXFP1 expression. This would support treatment with relaxin agonists early in the course of the disease. Further study is needed, as the potential to increase RXFP1 expression in fibrosis may sensitize patients to the therapeutic effects of relaxin.

The distinct transcriptomic profiles of the RXFP1-high patients compared with the $R X F P 1-l o w$ patients may identify clinically distinct subphenotypes of patients with IPF. The LTRC dataset, which is unique, is limited by a lack of longitudinal follow-up or a replication cohort. Therefore, we can only speculate as to the prognostic significance of RXFP1 expression; however, the association of RXFP1 with FVC, the best validated marker of disease progression in IPF (33), does suggest that the high expressers of RXFP1 are indeed "better." Another limitation of this analysis is that our assessment of $R X F P 1$ requires tissue. As the number of surgical lung biopsies for ILD (34) decreases, replication of this study may be challenging in the absence of a surrogate biomarker for RXFP1 that can be sampled from the circulation. We did observe a small but statistically significant increase in $R L N 2$ gene expression. However, unlike for $R X F P 1$, we found no association of $R L N 2$ gene expression with pulmonary function. A small study published as an abstract suggested that plasma relaxin concentrations in IPF were associated with FVC (35). Thus, the role of plasma relaxin and pulmonary function remains an open question that merits further study.

Initial enthusiasm for the antifibrotic effects of relaxin in $\operatorname{SSc}(8,11,36)$ was ultimately dampened by the failure of relaxin in SSc (9). Our data showing that RXFP1 expression is decreased in patients with IPF suggests that only a subset of patients with the highest expression of RXFP1 would be predicted to respond to relaxin-based therapies. Treating RXFP1low patients with escalating doses of relaxin may predispose them to adverse effects. The decrease in RXFP1 that we observed in SSc and the association of RXFP1 with pulmonary function across non-IPF ILDs and IPF support the hypothesis that this mechanism is common to fibrotic diseases and needs to be further clarified to realize the therapeutic potential of relaxin.

Author disclosures are available with the text of this article at www.atsjournals.org.

Acknowledgment: The Human Airway Cell and Tissue Core (072506) and the Human Airway Cell and Tissue Core (Cystic Fibrosis Foundation Research Development Program Grant), under the direction of Joseph Pilewski and Mauricio Rojas, provided human lung fibroblasts.

\section{References}

1. Navaratnam V, Fleming KM, West J, Smith CJ, Jenkins RG, Fogarty A, Hubbard RB. The rising incidence of idiopathic pulmonary fibrosis in the U.K. Thorax 2011;66:462-467.

2. Raghu G, Chen SY, Yeh WS, Maroni B, Li Q, Lee YC, Collard HR. Idiopathic pulmonary fibrosis in US Medicare beneficiaries aged 65 years and older: incidence, prevalence, and survival, 2001-11. Lancet Respir Med 2014;2:566-572.

3. Yusen RD, Shearon TH, Qian Y, Kotloff R, Barr ML, Sweet S, Dyke DB, Murray S. Lung transplantation in the United States, 1999-2008. Am J Transplant 2010;10:1047-1068.

4. Chihal HJ, Espey LL. Utilization of the relaxed symphysis pubis of guinea pigs for clues to the mechanism of ovulation. Endocrinology 1973;93: 1441-1445.

5. Bennett RG. Relaxin and its role in the development and treatment of fibrosis. Trans/ Res 2009;154:1-6.
6. Samuel CS, Zhao C, Bathgate RA, Bond CP, Burton MD, Parry LJ, Summers RJ, Tang ML, Amento EP, Tregear GW. Relaxin deficiency in mice is associated with an age-related progression of pulmonary fibrosis. FASEB $J$ 2003:17:121-123.

7. Samuel CS, Zhao C, Bathgate RA, Du XJ, Summers RJ, Amento EP, Walker LL, McBurnie M, Zhao L, Tregear GW. The relaxin geneknockout mouse: a model of progressive fibrosis. Ann $N$ Y Acad Sci 2005;1041:173-181.

8. Seibold JR, Korn JH, Simms R, Clements PJ, Moreland LW, Mayes MD, Furst DE, Rothfield N, Steen V, Weisman M, et al. Recombinant human relaxin in the treatment of scleroderma: a randomized, doubleblind, placebo-controlled trial. Ann Intern Med 2000;132:871-879.

9. Khanna D, Clements PJ, Furst DE, Korn JH, Ellman M, Rothfield N, Wigley FM, Moreland LW, Silver R, Kim YH, et al.; Relaxin Investigators and the Scleroderma Clinical Trials Consortium. Recombinant human relaxin in the treatment of systemic sclerosis 
with diffuse cutaneous involvement: a randomized, double-blind, placebo-controlled trial. Arthritis Rheum 2009;60:1102-1111.

10. Teerlink JR, Cotter G, Davison BA, Felker GM, Filippatos G, Greenberg $\mathrm{BH}$, Ponikowski $\mathrm{P}$, Unemori E, Voors AA, Adams KF Jr, et al.; RELAXin in Acute Heart Failure (RELAX-AHF) Investigators. Serelaxin, recombinant human relaxin-2, for treatment of acute heart failure (RELAX-AHF): a randomised, placebo-controlled trial. Lancet 2013;381:29-39.

11. Bathgate RA, Halls ML, van der Westhuizen ET, Callander GE, Kocan M, Summers RJ. Relaxin family peptides and their receptors. Physiol Rev 2013;93:405-480.

12. Pini A, Shemesh R, Samuel CS, Bathgate RA, Zauberman A, Hermesh C, Wool A, Bani D, Rotman G. Prevention of bleomycin-induced pulmonary fibrosis by a novel antifibrotic peptide with relaxin-like activity. J Pharmacol Exp Ther 2010;335:589-599.

13. Hsu SY, Nakabayashi K, Nishi S, Kumagai J, Kudo M, Sherwood OD, Hsueh AJ. Activation of orphan receptors by the hormone relaxin. Science 2002;295:671-674.

14. Huang X, Gai Y, Yang N, Lu B, Samuel CS, Thannickal VJ, Zhou Y. Relaxin regulates myofibroblast contractility and protects against lung fibrosis. Am J Pathol 2011;179:2751-2765.

15. Heeg MH, Koziolek MJ, Vasko R, Schaefer L, Sharma K, Müller GA, Strutz $F$. The antifibrotic effects of relaxin in human renal fibroblasts are mediated in part by inhibition of the Smad2 pathway. Kidney Int 2005;68:96-109.

16. Bauer Y, Tedrow J, de Bernard S, Birker-Robaczewska M, Gibson KF, Guardela BJ, Hess P, Klenk A, Lindell KO, Poirey S, et al. A novel genomic signature with translational significance for human idiopathic pulmonary fibrosis. Am J Respir Cell Mol Biol 2015;52:217-231.

17. Herazo-Maya JD, Noth I, Duncan SR, Kim S, Ma SF, Tseng GC, Feingold E, Juan-Guardela BM, Richards TJ, Lussier Y, et al. Peripheral blood mononuclear cell gene expression profiles predict poor outcome in idiopathic pulmonary fibrosis. Sci Transl Med 2013; 5:205ra136.

18. Feghali-Bostwick CA, Tsai CG, Valentine VG, Kantrow S, Stoner MW, Pilewski JM, Gadgil A, George MP, Gibson KF, Choi AM, et al. Cellular and humoral autoreactivity in idiopathic pulmonary fibrosis. $J$ Immunol 2007;179:2592-2599.

19. Benjamini YH. Hochberg Y. Controlling the false discovery rate: a practical and powerful approach to multiple testing. J $R$ Stat Soc $B$ 1995; $57: 11$

20. Wu W, Dave N, Tseng GC, Richards T, Xing EP, Kaminski N. Comparison of normalization methods for CodeLink Bioarray data. BMC Bioinformatics 2005;6:309.

21. Pilewski JM, Liu L, Henry AC, Knauer AV, Feghali-Bostwick CA. Insulinlike growth factor binding proteins 3 and 5 are overexpressed in idiopathic pulmonary fibrosis and contribute to extracellular matrix deposition. Am J Pathol 2005;166:399-407.

22. Kass DJ, Yu G, Loh KS, Savir A, Borczuk A, Kahloon R, Juan-Guardela B, Deiuliis G, Tedrow J, Choi J, et al. Cytokine-like factor 1 gene expression is enriched in idiopathic pulmonary fibrosis and drives the accumulation of $\mathrm{CD} 4^{+} \mathrm{T}$ cells in murine lungs: evidence for an antifibrotic role in bleomycin injury. Am J Pathol 2012;180: 1963-1978.
23. Lekgabe ED, Kiriazis H, Zhao C, Xu Q, Moore XL, Su Y, Bathgate RA, Du XJ, Samuel CS. Relaxin reverses cardiac and renal fibrosis in spontaneously hypertensive rats. Hypertension 2005;46:412-418.

24. Nouraie M, Lee JS, Zhang Y, Kanias T, Zhao X, Xiong Z, Oriss TB, Zeng Q, Kato GJ, Gibbs JS, et al.; Walk-PHASST Investigators and Patients. The relationship between the severity of hemolysis, clinical manifestations and risk of death in 415 patients with sickle cell anemia in the US and Europe. Haematologica 2013;98:464-472.

25. Noble PW, Barkauskas CE, Jiang D. Pulmonary fibrosis: patterns and perpetrators. J Clin Invest 2012;122:2756-2762.

26. Hsu E, Shi H, Jordan RM, Lyons-Weiler J, Pilewski JM, FeghaliBostwick CA. Lung tissues in patients with systemic sclerosis have gene expression patterns unique to pulmonary fibrosis and pulmonary hypertension. Arthritis Rheum 2011;63:783-794.

27. Tanjore H, Cheng DS, Degryse AL, Zoz DF, Abdolrasulnia R, Lawson WE, Blackwell TS. Alveolar epithelial cells undergo epithelial-to-mesenchymal transition in response to endoplasmic reticulum stress. J Biol Chem 2011;286:30972-30980.

28. Fallowfield JA, Hayden AL, Snowdon VK, Aucott RL, Stutchfield BM, Mole DJ, Pellicoro A, Gordon-Walker TT, Henke A, Schrader J, et al. Relaxin modulates human and rat hepatic myofibroblast function and ameliorates portal hypertension in vivo. Hepatology 2014;59: 1492-1504.

29. Mookerjee I, Hewitson TD, Halls ML, Summers RJ, Mathai ML, Bathgate RA, Tregear GW, Samuel CS. Relaxin inhibits renal myofibroblast differentiation via RXFP1, the nitric oxide pathway, and Smad2. FASEB J 2009;23:1219-1229.

30. Mazella J, Tang M, Tseng L. Disparate effects of relaxin and TGF $\beta 1$ : relaxin increases, but TGF $\beta 1$ inhibits, the relaxin receptor and the production of IGFBP-1 in human endometrial stromal/decidual cells. Hum Reprod 2004;19:1513-1518.

31. Bond CP, Parry LJ, Samuel CS, Gehring HM, Lederman FL, Rogers PA, Summers RJ. Increased expression of the relaxin receptor (LGR7) in human endometrium during the secretory phase of the menstrual cycle. J Clin Endocrinol Metab 2004;89:3477-3485.

32. Tan YY, Wade JD, Tregear GW, Summers RJ. Quantitative autoradiographic studies of relaxin binding in rat atria, uterus and cerebral cortex: characterization and effects of oestrogen treatment. Br J Pharmacol 1999;127:91-98.

33. du Bois RM, Weycker D, Albera C, Bradford WZ, Costabel U, Kartashov A, King TE Jr, Lancaster L, Noble PW, Sahn SA, et al. Forced vital capacity in patients with idiopathic pulmonary fibrosis: test properties and minimal clinically important difference. Am J Respir Crit Care Med 2011;184:1382-1389.

34. Flynn M, Baker ES, Kass DJ. Idiopathic pulmonary fibrosis biomarkers: clinical utility and a way of understanding disease pathogenesis. Curr Biomark Find 2015;5:21-33.

35. Han MK, Hogaboam CM, Murray S, Flaherty KR, Toews GB, Martinez FJ. Plasma relaxin predicts FVC in IPF [abstract]. Am J Respir Crit Care Med 2009;179:A3014.

36. Casten GG, Boucek RJ. Use of relaxin in the treatment of scleroderma. J Am Med Assoc 1958;166:319-324. 